\title{
Is Creative Economy in Croatia a Myth or Reality? Some Evidence on the Impact of Creativity on Regional Economic Growth
}

\author{
Nebojša Stojčić \\ University of Dubrovnik, Department of Economics and Business \\ Economics, Croatia \\ nstojcic@unidu.hr
}

\section{Katarina Bačić}

The Institute of Economics, Zagreb, Croatia

kbacic@eizg.hr

\section{Zoran Aralica}

The Institute of Economics, Zagreb, Croatia

zaralica@eizg.hr

\author{
CroEconSur \\ Vol. 18 \\ No. 2 \\ December 2016 \\ pp. 113-138
}

Received: November 4, 2016 Accepted: November 22, 2016

Research Article

doi:10.15179/ces.18.2.4

\section{Abstract}

The objective of this paper is to explore the intraregional and interregional relationships between employment of creative individuals in creative industries and the economic growth of Croatian regions. Spatial panel analysis is applied to assess the interregional effects of regional growth as well as interregional and intraregional effects of cultural and creative industries on economic growth in 2006-2012. While there is empirical evidence of positive interregional economic growth effects, the contribution of the creative potential to the growth of Croatian regions is found to be negative. These findings can be explained by overall modest representation of creative industries, particularly in faster growing regions, and the growth impediments imposed on creative industries by Croatian producers that mostly compete in standardized price-competitive segments of the market.

Keywords: creative potential, creative industries, regional growth, Croatia

JEL classification: Z10, O15, R11, R12 


\section{Introduction}

Creativity has gained its momentum in economic policies in the European Union (EU) in the mid first decade of the $21^{\text {st }}$ century. National mapping reports on creative industries started to appear at this time. With its rich cultural history, traditional dedication to culture, art and associated activities, the EU is considered to have "the leading talent in cultural and creative industries" (EC, 2014: 2). Cultural and creative industries can be defined as economic activities that thrive on the creative contribution of their labor force. The economic power of fragmented activities constituting the "creative sector(s)" is clearly recognized in national reports. The political importance of creativity for European economy and society is communicated through the term "Creative Europe", signifying a program aimed at supporting European cultural and creative sectors for the period 2014-2020, amounting to the value of EUR 1.8 billion. However, the importance of the creativity platform was recognized even earlier, with the rise of the "creative class" and "creative economy" (Florida, 2002). For example, German cities and regions faced with a loss of competitiveness in traditional industries turned their attention to creative industries as early as the 1980s (Fesel and Söndermann, 2007).

International and national organizations have proposed and used their own definitions of creative industries. These industries appear under the term(s) "cultural and/or creative industries" and the scope of activities recognized as "creative" also differs. The British approach is most widely used across European countries, with some national modifications, as it has been most developed and investigated. After a policy consultation on creative industries in 2014, the Department for Culture, Media and Sport (DCMS) has redefined the list of creative industries and creative occupations for the United Kingdom. The broad nine economic areas that creative industries consist of in the UK are: (1) advertising and marketing; (2) architecture; (3) crafts; (4) design; (5) film, TV, video, radio and photography; (6) IT, software and computer services; (7) publishing; (8) museums, galleries and libraries; and (9) music, performing and 
visual arts (DCMS, 2014). Many reports on creative industries in European countries such as the United Kingdom, Germany, and Austria have been explicit on the fact that creative industries' growth rate has been more dynamic than those of some traditional industries. For example, in Germany in 2007, the contribution of creative and cultural industries to gross value added fell in the middle range when compared to some traditional industries. The contribution of creative industries is higher than that of the chemical industries and lower than that of the automobile industry (FMET, 2010). Furthermore, creative industries have to a certain degree resisted the recent European economic slowdown (Stumpo and Manchin, 2015). In Austria, creative industries have expanded their activities even after the economic slowdown in 2009 (KWA, 2013).

Innovation-based growth is an important political goal in Europe, and creative industries play a role in this political agenda. Creative industries are deeply integrated into economies, both through horizontal and vertical linkages. These linkages with other activities represent channels of spillover of creative input, boosting growth of various economic activities. Research of creative industries in Austria and Germany has shown that creative businesses cooperate intensely within their own sector, with motivation ranging from expanding capacities to networking. On the other hand, they provide innovative products and services to other sectors of the economy. Creative industries in some countries have shown to be more innovative than other sectors of the economy, for example in Austria (KWA, 2009). Through business cooperation creative industries participate in innovative activities of other sectors, in various phases of the activity, including the vitally important "idea-generating" phase. Given the fact that creative output is also based on specialist knowledge, cooperation with traditional economic sectors may also be seen as a channel of diffusion, transfer and application of knowledge to the other sectors of the economy. In Croatia, within the Smart Specialization Strategy (S3), creativity has been recognized as an important activity. According to this strategy, Croatia would be recognized as a knowledge- 
based economy, which promotes creativity and innovation at all levels of society (MINGO, 2014: 140).

The objective of this paper is to explore the role of creativity in the growth of Croatian regions. The advantage of the paper over the existing body of knowledge lies in its focus on spatial dimensions of both creativity and growth. To this end, a distinction is made between intraregional and interregional effects of economic performance and creative potential of individual regions on the growth and creativity of regions in their surroundings over the 2006-2012 period. To the best of our knowledge, there has been no previous attempt to address the relationship between creativity and growth in such a context. The paper is structured as follows. The next section provides the conceptual framework of the analysis. The preliminary analysis of spatial growth patterns and creative potential of Croatian regions is undertaken in Section three. Section four provides the model of empirical investigation and explains the used methodology while the obtained findings are discussed in Section five. Section six concludes.

\section{Conceptual Framework of the Analysis}

Weak recovery of national economies in the $\mathrm{EU}$ in the aftermath of the global crisis has been one of the causes for recognizing creative industries as one of the new key industries. Another impetus came from the process of transition towards the intangible assets-based economy (Pitelis, 2014), whereby the production of new knowledge presents a response of firms and individuals to changing environment through the modification of existing and introduction of new modes of behavior (Nelson and Winter, 1982; Barney, 1991). This approach requires more creative effort, i.e., transformation of ideas of individuals into innovative products and/or services (Schumpeter, 1934), in comparison to the past where economic activity relied on tangible assets (e.g., machinery and equipment). Creative industries are increasingly being recognized as one of the most dynamic sectors in the modern 
knowledge-based economy, in the EU, on national and/or subnational level (EC, 2010).

Factors that have enabled the growth of these industries are the development of ICT and efficient systems of intellectual property (IP) protection. Creative industries are closely related to the concept of copyright industries. The investment into "creative input", as a nonmaterial asset, can efficiently be protected and commercialized through copyright protection. Thus industries that use copyrights in protecting their investments are considered copyright industries. In many countries industries identified as copyright industries are considered creative industries. Although this view of creative industries may be too narrow, as creative industries have developed alternative methods of protecting the original creativity in their products, such as "first-mover advantage" where brand, distinctiveness and novelty play the key role (Bakhshi, Freeman and Higgs, 2013), the importance of IP for creative industries makes these industries closely related to the concept of use of knowledge.

Creative activities are based on "creative input" that can be considered an intangible asset, and largely associated with service industries. Intangible assets such as ideas, knowledge and information are crucial for the increase of firms' value added (EC, 2010). Research has shown that within service industries, knowledge-intensive services in a region can prove to be a decisive factor in creating competitive advantages by boosting innovation activities and output. This can be explained by the fact that "knowledge" is spatially sticky. More specifically, knowledge-intensive business services (KIBS) that include certain creative activities such as design and market research, have played a role for the innovation potential of progressive European regions (Corrocher and Cusmano, 2014).

The role of creative industries is also regarded in a wider development context. UNESCO (2012) summarizes a broad overview of various economic and noneconomic impacts of creative industries identified in empirical literature and 
policy documents. The noneconomic impacts are seen in the following: social cohesion and integration of marginalized groups, building of a new value system, affirmation of creativity, talents and excellence, development of cultural diversity, national identity and the identity of different cultural groups, facilitating creativity and innovation. The economic impacts of creative industries are created through generating value added and employment, exporting, regeneration and branding of creative cities and contributing to urban attraction forces.

For a post-transition economy, an important contribution from creative industries may be seen in their role in regeneration of mature industries, as shown in the case of the Swiss watchmaking industry (Jeannerat and Crevoisier, 2013). A broader impact of creativity can also be seen in the promotion of absorbing capacity through knowledge creation and/or knowledge acquisition. For example, creativity may facilitate social innovations - as an idea which should display positive impact on the quality and/or quantity of life (Pol and Ville, 2009) and creation of new social relationships and collaborations (Murray, CaulierGrice and Mulgan, 2010). Lee (2014) notes that creative industries generate agglomeration externalities and thus drive both employment and wage growth in other sectors while at the same time squeezing out declining industries from urban areas. Finally, evidence from Marrocu and Paci (2012) for more than 257 regions of EU-27 countries reveals that employees in creative industries stand as the most relevant component in explaining regional economic performance defined as total factor productivity.

Key drivers of creative industries are "human creativity and innovation, at both the individual and group level" (UNESCO and UNDP, 2013: 15). Creative professionals' contribution to creative industries is central to their success, and the quality and availability of skills in generating services in these industries (Gallouj et al., 2014). Creative human capital is present in all economic activities. Creative professionals can be identified across all activities as they are employed in creative occupations. However, the largest concentration of creative professionals is in creative industries. That is the reason why access to specialized 
labor markets is relevant for creative industries and that is why creative industries are mostly associated with large urban areas. However, these industries also bear the potential for the development of less urban areas and even rural areas as they can help the survival of traditional forms of economic activity and thus lead to economic viability of such areas. New technologies have provided a possibility for these industries to be located in less urban regions. For example, in Austria, 18 percent of creative businesses are located in rural areas (KWA, 2013). Another benefit of creative industries' development in less urban and rural regions is the change that they can bring about in the negative migration pattern whereby labor force migrates from less developed regions towards larger cities of regional importance or capital cities. A similar pattern may be observed with firms that are attracted by agglomeration forces. Creative professionals' migration that may arise as a result of industry relocation can facilitate creativity and innovation in new locations/regions.

The social and cultural significance of creative industries in Croatia has previously been widely researched (Švob-Đokić, 2005; Švob-Đokić, Primorac and Jurlin, 2008; Jelinčić and Žuvela, 2013). The first attempt to measure the economic significance of the creative sector in Croatia can be recognized in the study of the State Intellectual Property Office of the Republic of Croatia published in 2007. It dealt with the economic contribution of copyright industries in Croatia between 2002 and 2004, providing the first valuable information on the significance of copyright industries in the country (DZIV, 2007). Moreover, cultural and creative industries in Croatia have started to be perceived as a sector publicly in the last two years, along with the setting up of the Croatian Cluster of Competitiveness of Cultural and Creative Industries (CCCCCI) that has intensely promoted the sector.

Results of the first national mapping report on cultural and creative industries in Croatia were presented in May 2015, under the auspices of CCCCCI. The mapping report provided the first estimations of the economic significance of cultural and creative industries - these industries generated gross value added 
(GVA) in the amount of HRK 6.3 billion or 2.3 percent of GDP in 2012, while their share in employment was at 3 percent in 2014. The largest subsectors in terms of value added (in 2012) and in terms of employment (in 2014) are publishing, electronic media, museums, galleries and libraries, IT, computer games and new media, advertising and market communications, and music, visual and performing arts. GVA generated by firms in cultural and creative industries in Croatia rose by 3.5 percent nominally in the 2009-2013 period, while at the same time GVA of all Croatian firms decreased by 4.7 percent nominally (Rašić Bakarić, Bačić and Božić, 2015).

Table 1: Share of Selected Cultural and Creative Industries in Gross Value Added (GVA) and Employment in 2012

\begin{tabular}{l|c|c}
\hline Sector & GVA share, in \% & Employment share, in \% \\
\hline Publishing & 19.9 & 21.1 \\
\hline Electronic media & 18.2 & 12.8 \\
\hline Museums, galleries and libraries & 14 & 11.2 \\
\hline IT, computer games and new media & 13.7 & 10.4 \\
\hline Advertising and market communications & 11.8 & 14.0 \\
\hline Music, visual and performing arts & 11.7 & 13.2 \\
\hline
\end{tabular}

Source: Rašić Bakarić, Bačić and Božić, 2015.

Moreover, within the Smart Specialization Strategy (S3), creative and cultural industries have been recognized as a cross-cutting theme and at the same time creativity represents a crucial source of innovation for the thematic priority areas ${ }^{1}$ (MINGO, 2014: 307). However, the dynamic economic aspects of creativity and creative industries in Croatia and in Croatian regions have not been researched yet.

1 These are: transport and mobility, energy and sustainable environment, security, bio-economy, health and quality of life and agro-food. 


\section{Growth and Creativity in Croatian Regions}

Economists have for a long time recognized the interrelatedness of economic activity across space. The roots of such reasoning are commonly attributed to the "new economic geography" (NEG) (Krugman, 1991). NEG models postulate that the initial distribution of economic activity across space takes place randomly. However, the occurrence of idiosyncratic shocks distorts this initial equilibrium and leads to spatial concentration of economic activity. Over time such occurrences give rise to accelerating spatial clustering and enable some spatial areas (e.g., regions) to become more prosperous and perform better than other counterparts. Further spatial clustering takes place through cooperation between firms in prosperous regions and their counterparts in neighboring areas as well as through the intraregional migration of workforce. The general message coming from NEG literature is that due to certain historical events some areas (regions) will perform better than others. Such development may lead also to interregional effects as migration of workforce and vertical and horizontal spillovers from firms in advanced regions exert positive influence on their rivals in other areas. Such effects will particularly be emphasized in neighboring areas as previously mentioned spillover effects tend to be localized (Jaffe, Trajtenberg and Henderson, 1993).

Figure 1 presents growth of Croatian counties defined as change in GDP per capita over the 2006-2012 period. Although one would expect the largest rates of growth to be recorded in the most developed areas around major agglomerations, this happens only to be the case with Rijeka and Zagreb. The largest rates of growth are observed in several eastern regions. However, the most important finding is spatial clustering of regions with high economic performance and those with low economic results. 
Figure 1: GDP per Capita Growth in Croatian Regions, 2006-2012, in \%

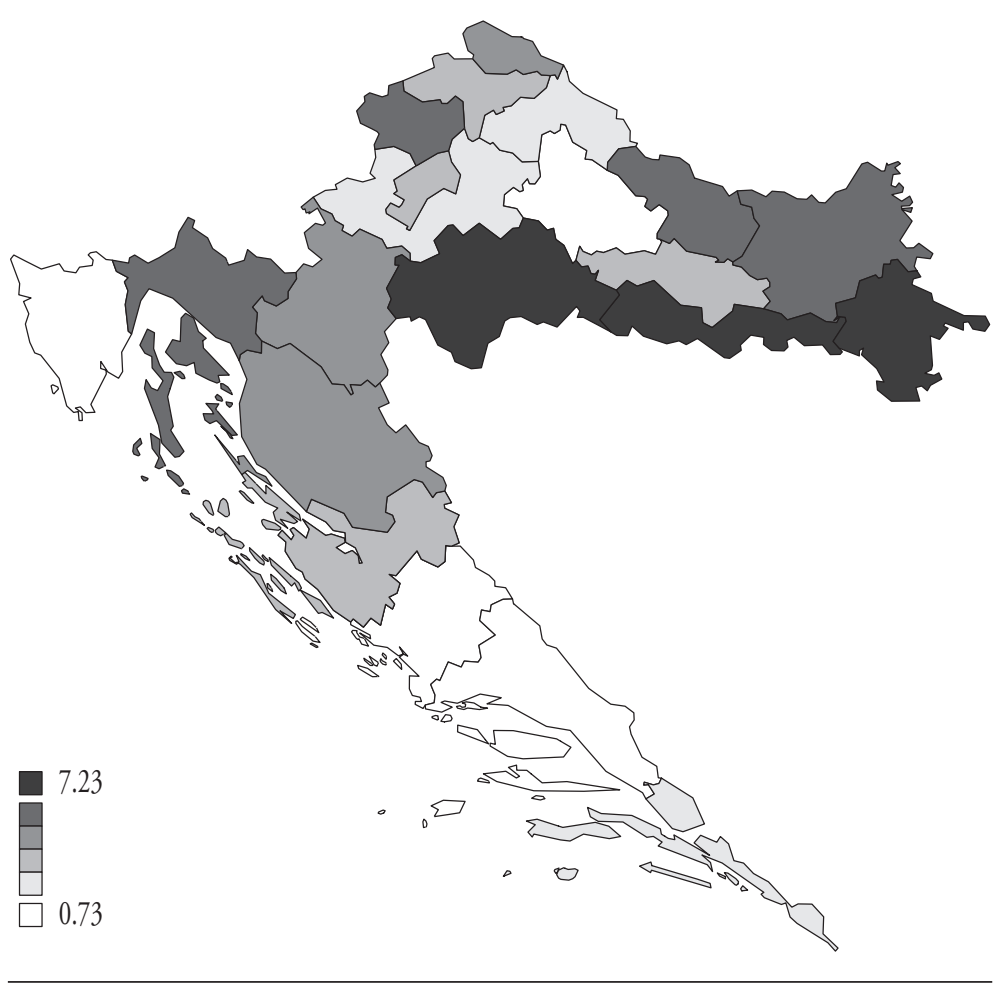

Source: Eurostat.

The discussion in previous sections suggests that the creative potential of economic units has important implications for their performance. In the regional context, it can be argued that creativity contributes to overall economic performance through the direct contributions of creative individuals to their firms and industries. However, equally important is the impact of firms and industries with creative potential on their less creative counterparts. The diffusion of knowledge that takes place, through interactions between suppliers and distributers as well as through competition channels and workforce movement, between firms and between different geographic areas presents a valuable source of competitiveness. 
Hence the benefits of creativity are not only accrued to firms with creative potential but generate positive externalities to other sectors as well.

The above reasoning has important implications in the context of regional economic performance. On the one hand, creativity generates positive intraregional effects. On the other hand, interactions between firms are not limited within regions but also take place across regional borders and the previously mentioned spillover effects may be of interregional type. The above suggests that regional creative potential may also be spatially clustered. However, adverse effects may also take place as higher opportunity of employment in creative professions and better economic climate may trigger migration of individuals and firms towards regions with higher creative potential, lowering creative potential and growth prospects of other regions.

The creative potential of regions can be assessed in several ways. On the one hand, all industries require employees in certain professions that can be regarded as creative. The information on such type of employment is generally not available at the regional level, and existing databases such as labor force surveys involve proportion rather than population of enterprises and employees, which makes them unsuitable for regional analysis. A far more feasible approach is the one concerned with the role of creative industries in regional economic performance. According to the British Department for Culture, Media and Sport (2014), there are a total of 31 creative industries that can be classified in the nine broad groups (advertising and marketing, architecture, crafts, design, movie, TV and cinema, IT services, publishing, museums, galleries and libraries and music and visual arts). 
Figure 2: Creative Potential of Croatian Regions, 2006-2012, Share of Employment in Creative Industries, in \%

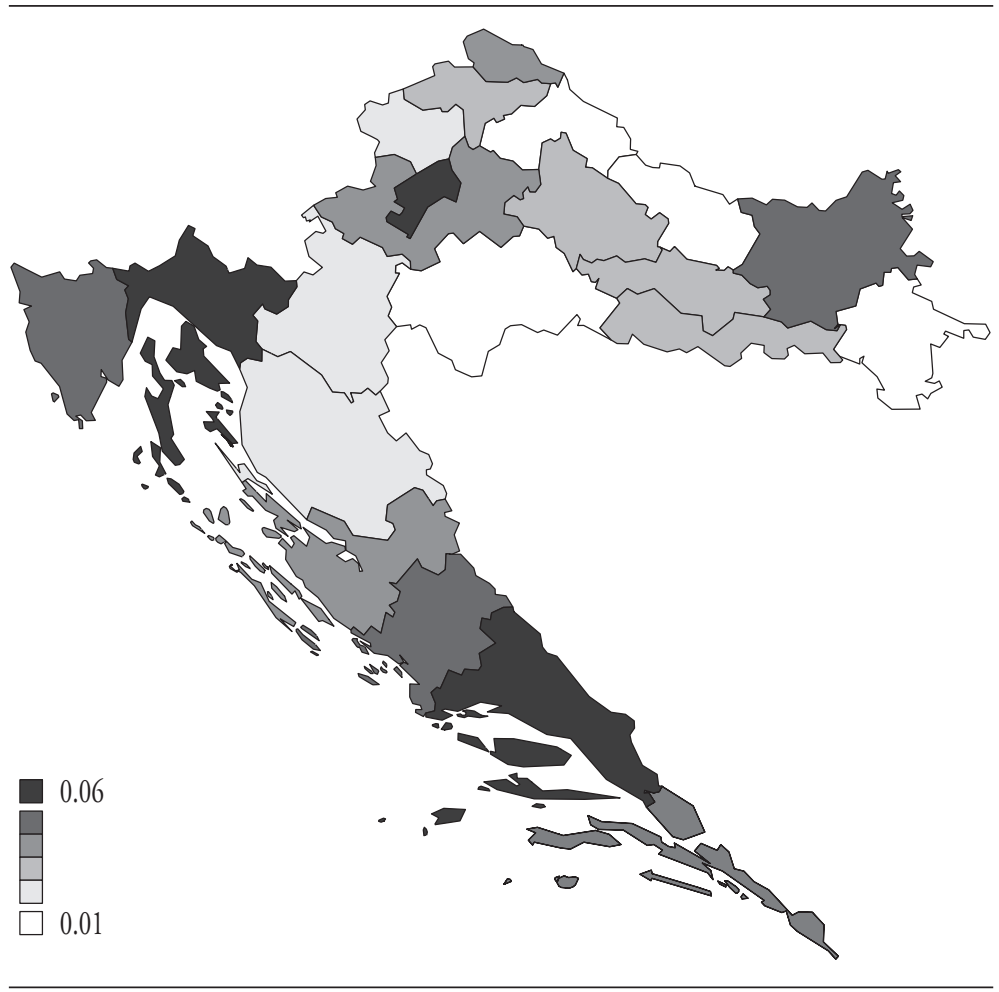

Source: Authors' calculations.

The above described classification has been applied to data from the Amadeus database provided by Bureau van Dijk in order to assess the creative potential of Croatian regions. The advantage of this database is that it provides a variety of information on firms, including industry in which they operate as well as their number of employees. Using these data, a measure of regional creative potential has been constructed as the ratio between the number of employees in creative industries and the total number of employees in a given region and year. The results of this analysis are presented in Figure 2. Spatial visualization signals that the most creative regions over the 2006-2012 period were located around the 
four largest metropolitan areas, namely Zagreb, Split, Osijek, and Rijeka, and to a lesser extent in other urban areas. Other regions generally exhibit lower traits of creative potential. To this end, it is worth mentioning that overall the share of workforce employed in creative industries is relatively low, with figures in the most creative regions ranging from five to six percent. Such a finding should not come as a surprise. Findings from many earlier studies point to the fact that Croatia is a producer of labor-intensive standardized goods.

\section{Model and Methodology}

Bearing the above said in mind, the objective of this section is to explore the role of creative industries in regional economic growth while taking into account both intraregional and interregional effects. For this reason, a model is developed that in general form can be expressed as:

$$
\begin{aligned}
\text { growth }_{j t}= & c_{0}+\rho \sum_{k=1}^{n} w_{j k} \text { growth }_{k t}+\beta_{1} \text { creative potential }_{i t}+\beta_{2} \text { population density }_{i t}+ \\
& +\theta_{1} \sum_{k=1}^{n} w_{j k} \text { creative potential }_{j t}+\theta_{2} \sum_{k=1}^{n} w_{j k} \text { populationdensity }_{j t}+\lambda \sum_{k=1}^{n} \varepsilon_{k t}+u_{i t} .
\end{aligned}
$$

The dependent variable in equation 1 is regional annual growth rate of GDP per capita taken from Eurostat. On the right hand side, the model includes the index of regional creative potential defined as the ratio between the number of employees in creative industries and total regional employment. Hence, the first hypothesis of the paper states that there is a statistically significant relationship between the region's creative potential and its rate of growth. A positive sign on this variable would signal that creative industries can be considered as drivers of regional growth. However, bearing in mind the low proportion of these industries in the Croatian economic structure as well as findings from earlier literature about the competitive profile of Croatian economy, a negative sign can also be expected. For this reason there is no prior expectation about the sign of this variable. 
The model also includes a variable defined as population density of the region. It was noted already by Marshall (1920) that more densely populated areas offer better prospects for the flourishing of economic activity. According to this reasoning, greater concentration of population presents a source of potential demand. In turn, this may act as an incentive for entrepreneurs to base their activity in such areas. Density of population may also be associated with higher pool of workforce. For these reasons, a positive sign can be expected for this variable and the second hypothesis posits that there is a positive relationship between the region's population density and its growth.

In addition to the above described intraregional effects, the model in equation 1 also controls for interregional ones. To this end, the third hypothesis of the paper states that there is a statistically significant relationship between the economic performance of individual regions and the performance of their counterparts. Better economic performance of some regions may exert a positive effect on their neighboring regions through vertical and horizontal linkages between firms and flow of skilled workforce. In a similar vein, Lall (2000) notes that the competitive profile of some areas may have an impact on the economic performance of other areas. Large urban areas are commonly labeled as suitable for firms in technology-intensive sophisticated industries. The competition in these industries tends to be quality-driven and they are characterized by higher costs of labor and other inputs. For these reasons firms in less sophisticated, price-competitive industries will favor location in smaller areas where lower business costs can be achieved. Hence, the effect of processes taking place in one region on the processes in another region (such as performance) will depend on the competitive profiles of both regions. Finally, it should be noted that better economic performance of some regions may have an adverse effect on other areas through migration of workforce and entrepreneurs towards areas with greater demand and better business opportunities. For these reasons, there is no a priori expectation on the sign of this variable. 
It has been noted by some of the earlier studies mentioned in Section 2 that creative industries can exert spillover effects to other sectors which in turn can translate into better economic performance. The above reasoning can be applied in the formulation of the final two hypotheses of the paper. Two variables are included to measure the interregional effects of creative potential and population density. Accordingly, the fourth hypothesis claims that greater creative potential of individual regions has an adverse effect on the economic performance of other regions. On the one hand, greater creative potential of some areas acts as an incentive for individuals in other areas to move, thus having a negative effect on the economic performance of the latter areas (regions). Furthermore, creative industries are often labelled as sophisticated knowledgeintensive sectors. In countries whose producers mainly compete in standardized price-competitive market segments, both intraregional and interregional negative effects of creativity on economic growth could be expected due to the inability of producers in those branches to position themselves in their market segment against established (mainly imported) products and services. Finally, greater population density of some areas can be associated with the previously mentioned demand effects and greater availability of workforce. Thus, the fifth hypothesis states that there is a positive interregional impact of population density on regional growth.

The estimation of the described model is undertaken with the spatial Durbin panel econometric technique. An advantage of this technique is its ability to control for spatial effects in both the dependent and independent variables as well as in the error term. The coefficients $\theta_{1}$ and $\theta_{2}$ in this context refer to spatial lags of explanatory variables while the coefficient $\rho$ is the measure of the impact of spatial lag on changes in the dependent variable of a given region. An important issue in spatial econometric analysis is the selection of spatial weights matrix W that defines spatial relations among cross-sectional units (Anselin, 1999; LeSage, 1998; 1999). For the purpose of this analysis, an inverse distance spatial weights matrix is used, where $w_{i j}$ is defined as inverse distance between regional centers 
and full spatial correlation is allowed (Baltagi, Egger and Pfaffermayr, 2007). Following common practice, row standardization is performed with elements $w_{i j}$ of each row having the sum of 1 (Olejnik, 2008).

\section{Discussion of Findings}

The starting point in the analysis is examination of model diagnostics in order to establish the validity of reported results. To this end, the most important diagnostics are those related to spatial correlation between the dependent and independent variables and the error term. Information in Table 2 suggests that the reported value of coefficient falls within an acceptable range. As noted by Olejnik (2008), such a finding can be interpreted as evidence of the dependent variable following a spatially integrated process $\operatorname{SI}(0)$. Further testing is performed with likelihood ratio (LR) tests on the spatially lagged dependent variable and spatial lags of regressors. The reported diagnostics reveal that null hypotheses of both the spatially lagged dependent variable and spatial lags of regressors can be rejected with very high probability. Several authors note that in such a case spatial estimation techniques should be preferred over conventional ones (Elhorst, 2013; Shehata and Mickaiel, 2014). Finally, testing is performed for the selection of the proper spatial estimator with conventional and robust LM tests (Burridge, 1980; Anselin, 1988). Common procedure suggests that the spatial Durbin model should be given preference when LM tests for both spatial lag and spatial error are significant or the conventional LR tests and robust LM tests point to different models (Elhorst, 2010; Shehata and Mickaiel, 2014). All tests indicate that the spatial Durbin model should be given preference over other spatial estimators. 
Table 2: Model Diagnostics

\begin{tabular}{l|c}
\hline Number of observations & 147 \\
\hline Number of units (regions) & 21 \\
\hline Log likelihood function & -232 \\
\hline Wald test & $11.25^{* * *}$ \\
\hline LR test SDM vs. OLS & $26.98^{* * *}$ \\
$H_{0}:(\rho=0)$ & $7.15^{* *}$ \\
\hline LR test & $0.001^{* * *}$ \\
$H_{0}:\left(w X^{\prime} S=0\right)$ & \\
\hline$\rho$ & $-0.006<\rho<0.002$ \\
\hline Acceptable range for $\rho$ & \\
\hline Spatial error autocorrelation tests & \\
H$_{0}:$ (no spatial error autocorrelation) & \\
\hline Global Moran MI & $0.65^{* * *}$ \\
\hline Global Geary GC & $0.32^{* * *}$ \\
\hline Global Getis-Ords GO & $-10.57^{* * *}$ \\
\hline LM error (Burridge) & $166.33^{* * *}$ \\
\hline LM error (robust) & 0.34 \\
\hline Spatial lagged dependent variable tests & \\
\hline$H_{0}:$ (no spatial autocorrelation) & \\
\hline LM lag (Anselin) & $187.71^{* * *}$ \\
\hline LM lag (robust) & $21.72^{* * *}$ \\
\hline General spatial autocorrelation tests \\
Ho $:$ no general spatial autocorrelation)
\end{tabular}

Note: ${ }^{* * *},{ }^{* *}$ and ${ }^{*}$ denote statistical significance at 1,5 , and $10 \%$ significance level, respectively. Source: Authors' calculations.

The reported diagnostics can be interpreted as evidence of the robustness of the model and pave the way for discussion of the findings. These are presented in Table 3. As can be seen there, a positive and statistically significant sign of the spatial lag of the dependent variable is obtained. These findings can be interpreted as direct evidence of spatial clustering of the best performing regions on the one hand and less successful regions on the other. Furthermore, it can be taken as a signal of positive interregional spillover effects described earlier such as flow of human capital or vertical and horizontal linkages between firms across regions. 
Table 3: Results of Estimation

\begin{tabular}{l|c}
\hline Variable & \\
\hline Spatial lag of dependent variable & $0.001^{* * *}$ \\
Creative potential & $-1.43^{*}$ \\
Population density & $0.01^{*}$ \\
Creative potential - spatial lag & $-0.01^{* *}$ \\
Population density - spatial lag & $0.0001^{*}$ \\
Constant term (cons) & $11.97^{* * *}$ \\
\hline
\end{tabular}

Notes: ${ }^{* *},{ }^{* *}$ and ${ }^{*}$ denote statistical significance at 1,5 , and $10 \%$ significance level, respectively. Robust standard errors used.

Source: Authors' calculations.

Turning to the most important issue, the impact of creative potential on regional economic growth, in the case of both intraregional and interregional effects a negative sign is obtained. Such a finding should not be a surprise if one takes into account the evidence reported in Section 3. As was established there, the best performing regions are generally not those characterized by larger proportion of creative industries. Furthermore, the overall modest representation of these industries in Croatian economy may be another reason for the obtained finding. Finally, it needs to be mentioned again that a likely reason for our finding could be the overall competitive profile of Croatian economy. The penetration of quality-driven segments of the market is a lengthy and challenging process whose success does not depend only on the behavior of firms but also on the overall perception of the market about goods and services offered. For many years Croatian producers have predominantly competed in standardized pricecompetitive segments of the market. Such reputation may act as an impediment for firms which attempt to position themselves in quality-driven segments of the market and erode their competitiveness, with consequent adverse effect on overall regional economic performance.

Finally, a positive sign is obtained on both variables controlling for the population density of the region. On the one hand, this signals that more populated regions provide a greater source of demand and wider pool of workforce. As noted 
previously, such conditions pave the way for economic activity. Moreover, a positive sign of the spatial lag suggests that positive effects of densely populated regions spill over to the economic performance of neighboring areas. Cooke and Morgan (1993) note that these spillovers depend on historical factors such as business culture, locational information networks and general knowledge about doing business. The similarities between neighboring regions make the above mentioned interactions easier than those between economic agents in distant areas.

\section{Conclusion}

The past decade has witnessed an upsurge of interest in the relationship between creativity and economic performance of firms, industries, regions and economies. The roots of such interest lie in the argument that creativity is the seedbed of innovation. It is being suggested that the ability to unlock the creative potential of economic agents offers much higher prospects for differentiation and economic growth. For this reason, a substantial amount of work has been undertaken with the aim of identifying professions and industries with greater creative potential. As a result of these efforts, a number of economic sectors are today classified as creative industries. However, while the beneficial effect of these sectors on economic performance is often emphasized in theoretical work, the empirical evidence is rather ambiguous. It seems that the ability to exploit the creative potential of the economy depends on a wide range of factors aside from specialization in creative industries and efforts to stimulate the creativity of individuals.

The objective of this paper was to explore the spatial dimension of the growth of Croatian regions by paying special attention to the role of creative potential. While the economic behavior of Croatian regions has been investigated from many aspects, the role of interregional effects has not been addressed. As noted earlier, there are several reasons why the economic performance of some regions 
may have important implications for other regions, particularly those in their immediate surroundings. Furthermore, while the importance of creativity for economic performance has been recognized by researchers for some time, the topic has been largely unaddressed in the Croatian context, with hardly any reference to it being made in regional research. This is particularly true for creative industries whose role in Croatian economy is largely unexplored. To the best of our knowledge, this study represents the first attempt to address the intraregional and interregional effects of creative industries on regional growth in general.

The obtained insights provide support to the chosen research approach. There is evidence of interregional performance effects, with improvements in the growth of some regions having beneficial effects on other regions. The existence of interregional effects has important implications for regional policy-makers who in shaping their policies must also take into account the conditions in their surroundings. Moreover, future regional research should address the spatial effects of numerous other drivers of growth aside from creative potential. However, the most important finding of our analysis is a negative contribution of the creative potential to the growth of Croatian regions. The competitiveness of firms in these industries depends on internal efforts, but also on a number of external factors such as overall perception of producers coming from a region or country. The established perception of Croatian firms as producers of standardized goods and services may present a serious impediment to the efforts of creative industries to position themselves on the market, as the competitiveness of these industries is mainly quality-driven.

While addressing this previously untackled topic, our research has several important limitations. Primarily these relate to the lack of available data on the regional level and inability to explore additional avenues of research on creativity. Future research should address the role of creative individuals in firms from other Croatian industries. Moreover, future analysis should take into account the ways through which firms employ individuals with creative potential and 
the methods used to stimulate the creativity of employees. Equally important is exploration of indirect channels through which creativity can influence regional and national growth such as innovation or attraction of foreign direct investment. Finally, future research should investigate the role of regional factors which can help unlock creative potential such as migration or education. These recommendations for future research may provide more comprehensive insight and policy recommendations for the development of creative economy in Croatia.

\section{Literature}

Anselin, Luc, 1988, Spatial Econometrics: Methods and Models, Dordrecht: Kluwer Academic Publishers. https://doi.org/10.1007/978-94-015-7799-1

Anselin, Luc, 1999, "The Future of Spatial Analysis in the Social Sciences", Geographic Information Sciences, 5(2), pp. 67-76. https://doi. org/10.1080/10824009909480516

Bakhshi, Hasan, Alan Freeman and Peter Higgs, 2013, A Dynamic Mapping of the UK's Creative Industries, London: NESTA, http://www.nesta.org.uk/sites/ default/files/a_dynamic_mapping_of_the_creative_industries.pdf (accessed February 9, 2015).

Baltagi, Badi H., Peter Egger and Michael Pfaffermayr, 2007, "Estimating Models of Complex FDI: Are There Third Country Effects?", Journal of Econometrics, 140(1), pp. 260-281. https://doi.org/10.1016/j.jeconom.2006.09.009

Barney, Jay, 1991, "Firm Resourcesand Sustained CompetitiveAdvantage", Journal of Management, 17(1), pp. 99-120. https://doi.org/10.1177/014920639101700108

Burridge, Peter, 1980, "On the Cliff-Ord Test for Spatial Autocorrelation", Journal of the Royal Statistical Society, 42(1), pp. 107-108.

Cooke, Philip and Kevin Morgan, 1993, "The Network Paradigm: New Departures in Corporate and Regional Development", Environment and Planning D: Society and Space, 11(5), pp. 543-564. https://doi.org/10.1068/d110543 
Corrocher, Nicoletta and Luica Cusmano, 2014, “The 'KIBS Engine' of Regional Innovation Systems: Empirical Evidence from European Regions", Regional Studies, 48(7), pp. 1212-1226. https://doi.org/10.1080/00343404.2012.731045

Department for Culture, Media and Sport (DCMS), 2014, Creative Industries Economic Estimates, Statistical Release, https://www.gov.uk/government/uploads/ system/uploads/attachment_data/file/271008/Creative_Industries_Economic_ Estimates_-_January_2014.pdf (accessed February 9, 2015).

Državni zavod za intelektualno vlasništvo Republike Hrvatske (DZIV) [State Intellectual Property Office], 2007, The Economic Contribution of the CopyrightBased Industries in the Economy of the Republic of Croatia [Ekonomski doprinos djelatnosti temeljenih na autorskom pravu u gospodarstvu Republike Hrvatske], Zagreb: DZIV.

Elhorst, J. Paul, 2010, "Spatial Panel Data Models" in Manfred M. Fischer and Arthur Getis, eds., Handbook of Applied Spatial Analysis, pp. 377-407, Berlin: Springer-Verlag. https://doi.org/10.1007/978-3-642-03647-7_19

Elhorst, J. Paul, 2013, "Spatial Panel Models" in Manfred M. Fischer and Peter Nijkamp, eds., Handbook of Regional Science, pp.1637-1652, Berlin: SpringerVerlag.

European Commission (EC), 2010, European Competitiveness Report 2010, Commission Staff Working Document SEC(2010) 1276, http://aei.pitt. edu/45443/1/competitiveness_2010.pdf (accessed March 9, 2015).

European Commission (EC), 2014, Communication from the Commission to the European Parliament, the Council, the European Economic and Social Committee and the Committee of the Regions: Research and Innovation as Sources of Renewed Growth, $\operatorname{COM}(2014) 339$ final, SWD(2014) 181 final, http://ec.europa. eu/research/innovation-union/pdf/state-of-the-union/2013/research-andinnovation-as-sources-of-renewed-growth-com-2014-339-final.pdf (accessed March 16, 2015). 
Federal Ministry of Economics and Technology (FMET), 2010, "Culture and Creative Industries in Germany 2009: Monitoring of Selected Economic Key Data on Culture and Creative Industries, Monitoring Report 2010 - Summary Version", Research Report, No. 589, http://www.kultur-kreativ-wirtschaft.de/ Dateien/KuK/PDF/culture-and-creative-industries-in-germany-2009-monitori ng,property=pdf,bereich=kuk, sprache $=$ de, rwb=true.pdf (accessed February 26, 2015).

Fesel, Bernd and Michael Söndermann, 2007, "Culture and Creative Industries in Germany, German Commission for UNESCO”, http://www.unesco.de/ fileadmin/medien/Dokumente/Bibliothek/culture_and_creative_industries.pdf (accessed February 27, 2015).

Florida, Richard, 2002, The Rise of the Creative Class: And How It's Transforming Work, Leisure, Community and Everyday Life, New York, NY: Perseus Book Group.

Gallouj, Faïz, K. Matthias Weber, Metka Stare and Luis Rubalcaba, 2014, “The Futures of the Service Economy in Europe: A Foresight Analysis”, Technological Forecasting and Social Change, 94, pp. 80-96. http://dx.doi.org/10.1016/j. techfore.2014.06.009

Jaffe, Adam, Manuel Trajtenberg and Rebeca Henderson, 1993, "Geographic Localization of Knowledge Spillovers as Evidenced by Patent Citations", The Quarterly Journal of Economics, 108(3), pp. 577-598. https://doi. org/10.2307/2118401

Jeannerat, Hugues and Olivier Crevoisier, 2013, "The Case of Cultural and Creative Enterprises in the Swiss Watchmaking Industry", in Luciana Lazzaretti, ed., Creative Industries and Innovation in Europe, pp. 232-250, London and New York, NY: Routledge, Taylor and Francis Group.

Jelinčić, Daniela A. and Ana Žuvela, 2013, "Što nas čini različitima? Kreativni Zagreb na putu prema kreativnoj Europi”, Media Studies, 4(7), pp. 75-92. 
Kreativwirtschaft Austria (KWA), 2009, Third Austrian Report on Creative Industries (Summary) - Focus on Creative Industries and Innovation, http://www. creativwirtschaft.at (accessed February 12, 2015).

Kreativwirtschaft Austria (KWA), 2013, Fifth Austrian Creative Industries Report (Short Version) - Focus: Creative Industries as a Regional Factor, http://www. creativwirtschaft.at (accessed February 15, 2015).

Krugman, Paul, 1991, "Increasing Returns and Economic Geography", Journal of Political Economy, 99(3), pp. 483-499. https://doi.org/10.1086/261763

Lall, Sanjaya, 2000, "The Technological Structure and Performance of Developing Country Manufactured Exports", Oxford Development Studies, 28(3), pp. 337-369. https://doi.org/10.1080/713688318

Lee, Neil, 2014, "The Creative Industries and Urban Economic Growth in the UK”, Environment and Planning A, 46(2), pp. 455-470. https://doi.org/10.1068/ a 4472

LeSage, James P., 1998, "Spatial Econometrics", Working Paper, Toledo: University of Toledo, Department of Economics.

LeSage, James P., 1999, "The Theory and Practice of Spatial Econometrics", Working Paper, Toledo: University of Toledo, Department of Economics.

Marrocu, Emanuela and Raffaele Paci, 2012, "Education or Creativity: What Matters Most for Economic Performance?", Economic Geography, 88(4), pp. 369-401. https://doi.org/10.1111/j.1944-8287.2012.01161.x

Marshall, Alfred, 1920, Principles of Economics, $8^{\text {th }}$ Edition, London: Macmillan and Co.

Ministarstvo gospodarstva (MINGO) [Ministry of Economy], 2014, "Smart Specialisation Strategy, Definition of Priority Areas”, draft version (mimeo). 
Murray, Robin, Julie Caulier-Grice and Geoff Mulgan, 2010, "The Open Book of Social Innovation", Social Innovator Series, London: NESTA and The Young Foundation.

Nelson, Richard R. and Sidney G. Winter, 1982, An Evolutionary Theory of Economic Change, Cambridge, MA: The Belknap Press of Harvard University Press.

Olejnik, Alicja, 2008, “Using the Spatial Autoregressively Distributed Lag Model in Assessing the Regional Convergence of Per-Capita Income in the EU25", Papers in Regional Science, 87(3), pp. 371-384. https://doi.org/10.1111/j.14355957.2008.00190.x

Pitelis, N. Christos, 2014, "Rejuvenating 'Old Europe': Towards a Strategy for Reindustrialisation and Sustainable Competitiveness", Contributions to Political Economy, 33(1), pp. 69-98. https://doi.org/10.1093/cpe/bzu009

Pol, Eduardo and Simon Ville, 2009, "Social Innovation: Buzz Word or Enduring Term?”, The Journal of Socio-Economics, 38(6), pp. 878-885. https:// doi.org/10.1016/j.socec.2009.02.011

Rašić Bakarić, Ivana, Katarina Bačić and Ljiljana Božić, 2015, "Mapping of Cultural and Creative Industries in the Republic of Croatia", Zagreb: The Institute of Economics, Zagreb, project study (mimeo).

Schumpeter, Joseph A., 1934, The Theory of Economic Development: An Inquiry into Profits, Capital, Credit, Interest, and the Business Cycle, Cambridge, MA: Harvard University Press.

Shehata, Emad Abd Elmessih and Sahra Khaleel A. Mickaiel, 2014, SPREGSDMXT: Stata Module to Estimate Maximum Likelihood Estimation Spatial Panel Durbin Regression, Statistical Software Components S457771, Boston College Department of Economics. 
Stumpo, Gulio and Robert Manchin, 2015, "The Resilience of Employment in the Culture and Creative Sectors (CCSs) during the Crisis", European Expert Network on Culture (EENC) Report, http://www.eenc.info/reports/theresilience-of-employment-in-the-culture-and-creative-sectors-ccss-during-thecrisis/ (accessed March 16, 2015).

Švob-Đokić, Nada, trans., 2005, “The Emerging Creative Industries in Southeastern Europe", collection of papers from the course "Managing Cultural Transitions: Southeastern Europe - The Impact of Creative Industries" organized by the Inter-University Centre, Dubrovnik, May 8-15, 2005, Zagreb: Institute for International Relations.

Švob-Đokić, Nada, Jaka Primorac and Krešo Jurlin, 2008, Kultura zaborava: industrijalizacija kulturnih djelatnosti [The Culture of Oblivion: The Industrialization of Culture], Zagreb: Naklada Jesenski i Turk and Hrvatsko sociološko društvo.

UNESCO, 2012, "Measuring the Economic Contribution of Cultural Industries: A Review and Assessment of Current Methodological Approaches", Framework for Cultural Statistics Handbook No. 1, Montreal: UNESCO Institute for Statistics, http://www.uis.unesco.org/culture/Documents/FCS-handbook-1economic-contribution-culture-en-web.pdf (accessed March 17, 2015).

UNESCO and UNDP, 2013, "Creative Economy Report, 2013, Special Edition: Widening Local Development Pathways”, http://www.unesco.org/ new/en/culture/themes/creativity/creative-economy-report-2013-special-edition (accessed March 17, 2015). 